\title{
Sanal Gerçeklik Ortamları ve Uygulamalar: Spor ve Sanal Ortam Göstergeleri
}

\author{
Volkan EKİN \\ Yrd. Doç. Dr. Volkan Ekin. İstanbul Kültür Üniversitesi, Sanat ve Tasarım Fakültesi, İletişim \\ Sanatları Bölümü, v.ekin@iku.edu.tr
}

ÖZET Günümüzde gerçeklik imgesi ile sanallık imgesi sık tartışılan kavramlar olmuştur. Gerçeğgin yansıması ya da "gerçekmiş" gibi yapılarak çeşitli uygulamalar gerçekleştirilmesi çoğu alanda gözlemlenmektedir. Gerçeğin göstergeleri ile "gerçekmiş" gibi aktarlan "şeylerin" göstergeleri farklı mıdır? Bu göstergelerin algılanmaları ve "gerçekmiş" gibi aktarılan dünyaların gerçek dünya göstergeleri ile bütünleşmesi ise gözlenen bir olgudur. Bu bağlamda, yeni medya teknolojileri ile yaratılan sanal ortamlarda yaşanan deneyimler, oluşturulan sanal dünyalar gerçek-gerçek olmayan karşıtlığını gözler önüne serse de, bu tür sanal dünyalar kimi alanlardaki uygulamalarla yaşamı da kolaylaştırmaktadır. Çalışmada örneğin; "robot göz" ya da simülasyon uygulamaları aracılı̆̆ıla teknolojik gelişmelerle yaratılan ve gerçek-sanal sınırın çizen, kimi zaman da sınırı aşan ortamlar, "spor etkinlikleri" bağlamında ele alınacaktır. Sporcularm performanslarn ve teknik özellikleri ile ilgili göstergeler, sanal ortama nasıl aktarıldığı; bu göstergeler anlamlandırıldiktan sonra, "gerçekte" nasıl bir iyileştirme ortamı yaratıldı̆̆ı sorusunun yanıtı sorgulanmaya çalışılacaktır.

Anahtar Kelimeler: Sanal gerçeklik, simülasyon, yeni medya teknolojileri, gösterge, spor.

\section{Virtual Reality Environments And Practices: Sports And Virtual Environment Indicators}

\begin{abstract}
These days, the image of reality and the image of virtuality are often being discussed. Reflection of the reality or carrying out various practices by pretending that they are real can be observed in many areas. Are the signs of reality different from the signs of the things which are shown as if they are real? Comprehension of these signs and integration of real world signs with the world which is shown as real is also an observed case. Within this context, although the experiences and virtual worlds created with new media technologies in virtual environment reveal the contrast between reality and unreality, these kinds of virtual worlds make life easier with practices in some areas. In the study, the environment which is created with technological advances like robot eye or simulation and the environment which draws a line or sometimes crosses the line between reality and virtuality will be discussed in the context of "sports activities". The signs about performances of sports people and technological features, how they are transferred to virtual environment; after being given meaning what kind of enhancement environment will be created in reality are the questions that will be examined and answered.
\end{abstract}

Key Words: Virtual reality, simulation, new media technologies, sign, sports. 
“Görme konuşmadan önce gelmiştir. Çocuk konuşmaya başlamadan önce bakıp tanımayı öğrenir."

John Berger

\section{Giriş}

Günümüzde gerçeklik imgesi ile sanallık imgesi sık tartışılan kavramlar olmuştur. Gerçeğin yansıması ya da "gerçekmiş" gibi yapılarak çeşitli uygulamalar gerçekleştirilmesi çoğu alanda gözlemlenmektedir. Gerçeğin göstergeleri ile "gerçekmiş" gibi aktarılan "şeylerin" göstergeleri farklı mıdır? Bu göstergelerin algılanmaları ve "gerçekmiş" gibi aktarılan dünyaların gerçek dünya göstergeleri ile bütünleşmesi ise gözlenen bir olgudur. Bu bağlamda, yeni medya teknolojileri ile yaratılan sanal ortamlarda yaşanan deneyimler, oluşturulan sanal dünyalar gerçek-gerçek olmayan karşıtlı̆̆ını gözler önüne serse de, bu tür sanal dünyalar kimi alanlardaki uygulamalarla yaşamı da kolaylaştırmaktadır.

Özellikle 1980'lerin sonlarından günümüze kadar yaşantımızda yoğun etkileri olan dijitalleşme; bir yandan yeni algılama biçimleri üretirken, aynı zamanda hem var olan, hem de türemekte ve evrilmekte olan söz konusu algilama biçimlerinin ifadesinde yeni olanaklar sunmaktadır.Beraberinde verilerini soyut bir alandan alan dijital ortam ve araçlar, referans çerçevelerimizle sınırlı olarak algıladığımız fiziksel gerçekliğin doğasını analiz etme, yorumlama, dönüştürme ve hatta yeni baştan kurabilme olanağı da sunmaktadır (Kuruüzümcü, 2010: s.93). Örneğin; "robot göz" ya da simülasyon uygulamaları aracılığıyla, teknolojik gelişmelerle yaratılan ve gerçek-sanal sınırını çizen, kimi zaman da sınırı aşan ortamlar, "spor etkinlikleri" bağlamında her geçen gün sporcuların performansları ve teknik özellikleri ile ilgili göstergeler biçiminde sanal ortama aktarılmakta ve bu göstergeler anlamlandırıldıktan sonra, "gerçekte" nasıl bir iyileştirme ortamı yaratıldı̆̆ı sorusunun yanıtı sorgulanmaya başlamıştır.

$\mathrm{Bu}$ iyileştirme çabalarında sanal gerçeklik ortamı; fiziksel gerçekliği yapay olarak yeniden üretmek ya da alternatif bir gerçeklik algısı yaratmak üzere, kullanıcıların duyularını oluşturulan ortamla etkileştirerek yönlendiren bir dijital veri uzamıdır. Teknoloji çağının dijital verileri üzerine inşa edilen sanal gerçeklik ortamları, kendine özgü karakter ve sınırları olan yeni “gerçeklik"ler tanımlamayı olanaklı kılmaktadır.

Gerçeklik kavramını, fiziksel gerçekliğin farklı algılanışlarınınöznel yorumu olarak ele aldığımızda, var olan ve algılanan arasındaki ilişkinin oldukça esnek ve yoruma açık olduğu gözlemlenmektedir. (Kuruüzümcü, 2010: s.93). Bu gerçeklik; teknoloji aracılığıyla elde edilen çeşitli verilerin analiz ve değerlendirmelerinde de kendini göstermektedir. Özellikle, spor kavramının endüstriyelleşmesi sürecindesporun teknoloji kavramı ile oluşmaya başlayan organik bağ çerçevesi göz önüne alındığında, sporcuların ve takımların tümdengelimli yapılarının değerlendirilmesi sonrasında gerek görüldüğ̈̈nde oluşan iyileştirilme ihtiyacl; bir başka deyişle yeniden üretimleri için teknoloji ve alt başlıkta da"sanal gerçeklik ortamları"başarıya giden yolda önem taşıyan araçlar olarak karşımıza çıkmaktadır.Bu 
sayede, özellikle insan faktörünün ve rekabetin bulunduğu spor ortamlarında teknolojinin, “oyuna” bu kadar dahil olması bile başlıbaşına bir tartışma konusu olmaktadır.

Günümüzde, spor kulüpleri ve sporcular, içinde bulundukları rekabet ortamlarında daha başarılı olmak ve sürekliliği olan başarıları yakalayabilmek adına çeşitli teknolojik imkanlardan her geçen gün daha fazla yararlanma yollarını araştırmakta ve uygulamada aşamasında cesur davranmaktan çekinmemektedirler.

Teknoloji ve sanal dünya ilişkisi söz konusu olduğunda Baudrillard'a göre; teknolojiyle yönlendirilen bir dünya yoktur, onun yerine sanal bir dünya bulunmaktadır. Her şeyin sanal olarak yaşandığı, mesafelerin belirsizleştiği, gerçek ve düş arasındaki sınırların yok olduğu, herkesin aynı sanallığ 1 yaşadığ ${ }_{1}$ simülakra bombardımanı altında bir dünya yaşanmaktadır ve bu dünyada teknoloji simülasyon ortamının kendisi olmaktadır(Yengin, 2012: s.61). Öyle ki, son yüzyılda bilim ve teknolojideki hızlı gelişmeler, dünya düzenini rekabetin içine sürüklemiş ve bu rekabet insanların var olan kaynakların şekillerinin değiştirilmesi imkanlarının ve sistemlerinin geliştirilmesine ve kullanılmasına neden olmuştur. Teknolojiyi kullanmak bir ayrıcalık olmaktan çıkarak, zorunluluk haline gelmektedir.

Özetle, sanal gerçeklik ve sanal dünya kavram ve uygulamalarının, hızla gelişim gösteren spor endüstrisine hizmet etmeye başladığı gözlemlenmektedir. $\mathrm{Bu}$ birliktelikte; göstergelerin, görsel algının, dijital göstergelerin ve simülasyonların,yeniden üretim ve gerçekliğin dönüşümünde sporcu ve takımların performanslarına olumlu etkileri üzerinde durulmaktadır.

\section{Göstergebilim ve Görsel Alg1}

İnsanların birbirleriyle anlaşmak için kullandıkları doğal diller, davranışlar, görüntüler, trafik işaretleri, bir kentin uzamsal düzenlenişi, bir müzik yapıtı, bir resim, bir tiyatro gösterisi, bir film, reklam afişleri, moda, sağır-dilsiz alfabesi, yazınsal yapıtlar, çeşitli bilim dilleri, tutkuların düzeni, bir ülkedeki ulaşım yollarının yapısı, bir mimarlık düzenlemesi, kısacası bildirişim amacı taşısın, taşımasın her anlamlı bütün, çeşitli birimlerden oluşan bir dizgedir.Gerçekleşme düzlemleri değişik olan bu dizgelerin birimleri de genelde, gösterge olarak adlandırılır. Yine çok genel olarak belirtecek olursak, anlamlı bütünleri, bir başka deyişle gösterge dizgelerini betimlemek, göstergelerin birbirleriyle kurdukları bağlantıları saptamak, anlamların eklemlenerek oluşma biçimlerini bulmak, göstergeleri ve gösterge dizgelerini sınıflandırmak, dolayısıyla insanla insan, insanla doğa arasındaki etkileşimi açıklamak, bu amaçla da bilimkuramsal, yöntembilimsel ve betimsel açıdan tümükapsayıcı, tutarlı ve yalın bir kuram oluşturmak gibi birbirinden farklı birçok araştırma Türkçe'de göstergebilim olarak adlandırılan bilim dalının alanına girmektedir (Rifat, 1990: s.83). Bu bağlamda; göstergebilimin temel konusunu oluşturan "gösterge"yi (sign) anlamadan göstergebilimi anlamanın imkansızlığı ile yüzleşilmektedir. Gösterge, "genel olarak bir başka şeyin yerini alabilecek nitelikte olduğundan, kendi dişında bir şey gösteren her türlü nesne, varlık ya da olgu"dur. Daha geniş bir tanımla, gösterge, insanların bir topluluk yaşamı içinde birbirleriyleanlaşmak amacıyla yarattıkları ve kullandıkları doğal diller (Türkçe, İngilizce, Fransızca vb.), çeşitli jestler (el, kol, baş hareketleri), sağır-dilsiz alfabesi, trafik işaretleri, bazı meslek gruplarında kullanılan flamalar, reklam afişleri, moda, mimarlık 
düzenlemeleri, yazın, resim, müzik gibi çeşitli birimlerden oluşan ve ses, yazı, görüntü, hareket gibi gereçler vasıtasıyla gerçekleşen dizgelerin oluşturduğu anlamlı bütünün birimleridir.Örneğin, bir tablodaki bir renk öğesi ya da bir figür bir gösterge olarak değerlendirilebileceği gibi, bir yazınsal yapıtta bir kahramanın amacı ya da davranışı, veya moda açısından bir bluz, bir etek, bir kazak vb. çevresindeki öbür birimlerle ilişkiye girmiş bir gösterge olarak değerlendirilebilir (Rifat, 1992: s.6).

Göstergebilim en kısa ve bilinen tanımıyla göstergelerin bilimidir. Saussure'e göre göstergebilim, "gösterge dizgelerinin bilimi anlamına geldiğine göre, gösterge kavramı ilke olarak bu bilimin temelidir... "How to Read a Film" isimli yapıtında James Monaco; göstergebilimin fizik, biyoloji gibi bir bilim dalı olmadığını, daha çok mantıksal olduğunu ileri sürmektedir (S. Parsa \& F.A. Parsa, 2004: s.1). Bu bağlamda göstergebilim, kültürel hayatın ve iletişimin önemli bir parçası olarak göstergeleri inceleyen bir araştırma alanıdır. Gösterge ve sistemlerini konu alanı seçerek, iletişim amaçlı her türlü gösterge dizgesinin yapısını ve işleyişini araştıran göstergebilim; kültürü anlamlandırma sürecinde göstergelerden yararlanmaktadır. Göstergelerin araştırılarak anlamlarının neler olduğunun ortaya koyulması, göstergelerin kullanım ilkelerinin belirlenmesi, etkilerinin açığa çıkarılması ve göstergelerin birbirleriyle kurdukları bağlantıların saptanması ile dizgeler arası sınıflandırmaların yapılarak insanla insan, doğayla insan arasındaki etkileşimin ortaya koyulması gerekmektedir (Altuntuğ, 2013: s.131).

Kuruluşu insanlık tarihinin başlangıcıyla ilişkilendirilse de, göstergebilime adını veren ilk kişi İngiliz filozof John Locke (1632-1704) olmuştur. “An EssayConcerning Human Understanding" (1690: İnsanın Anlama Yetisi Üzerine Bir Deneme) adlı eserinde ilk kez "semeiotike" terimini kullanarak "göstergeler öğretisi" olarak nitelediği semiyotiğin, bilimin üç temel branşından biri olması gerektiğini öne sürmüş ve bu göstergeler öğretisinin amacının, zihnin şeyleri anlamak ya da bilgilerini başkalarına anlatmak için kullandıkları göstergelerin niteliğini incelemek olduğunu savunmuştur (Deely, 1990: s.112).

Çağdaş göstergebilimin temelleri ise 20. yy. başlarında atılmaya başlamıştır. Amerikalı filozof Charles SandersPeirce (1839-1914) ve İsviçreli dilbilimci Ferdinand de Saussure (18571913) çağdaş göstergebilimin ilk temsilcileri olarak kabul edilmektedirler (Dervişcemaloğlu, 2005: s.11).

Mantıkçı ve aynı zamanda pragmatizmin kurucusu olan Peirce, semiotic terimini kullanarak genel bir göstergeler kuramı tasarlamış ve mantıksal işlevi üzerinde durmuştur.Saussure ise, dil dışındaki göstergelerin işlevsel yapılarının ve işleyişlerinin araştırılması gerekliliğini savunmuş ve yeni kurulacak bu bilim dalını Fransızca sémiologie terimiyle adlandırmıştır.

Peirce'nin mantıksal işlevini vurguladığı göstergeler, Saussure da toplumsal işlevleri yönüyle vurgulanmaktadır(www.ahmetozgur.com/akademik/gostergebilim2006.pdf,s.1517).Göstergenin gösteren ve gösterenden oluştuğunu ifade eden çağdaş dilbilimci ve göstergebilimin öncüsü Saussure, gösterileni göstergenin göndermede bulunduğu zihinsel bir kavram olarak tanımlamakta ve aynı dili paylaşan aynı kültürün mensupları için ortak payda olduğunu ifade etmektedir. Göstergebilimin gösterge ve gösterge dizgelerini inceleme alanı yaptı̆̆1 araştırmacıların ortak görüşüdür(Vardar, 1998: s.86-87). 
Eski Yunan felsefesinden başlamak üzere skolastik ortaçağ düşünürlerinden göstergebilime adını veren John Locke'a kadar göstergelerin anlamlarına yönelik birçok görüş ileri sürülmüştür. Temellerinin 20. yy. da atılmaya başlandığ çağdaş göstergebilim, Peirce ve Saussure'nin de katkılarıyla diğer araştırmacı, kuramcı, düşünürler tarafından benimsenmiş ve araştırma alanı olarak değerlendirmeye alınmıştır. Göstergebilimin araştırmacıların ilgisini çekmesi, birçok farklı yaklaşım ve her yaklaşımın kendi araştırma yöntemlerinin belirlenerek yeni tanım ve anlayışların ortaya çıkmasına sebep olmuştur.

Göstergebilim, 1960'lardan sonra geleneğini Peirce ve Saussure'den alan bağımsız bir bilim dalı haline gelmeye başlamıştır. Göstergebilim adıyla yapılan çalışmalar incelendiğinde birden fazla yaklaşım ve birçok alanda çalışmanın yapılmış olduğu görülmektedir.

Göstergebilimin gelişiminde birbirine yakın yaklaşımlar, araştırmacılar tarafından göstergebilim okul geleneğinin kurulmasına yol açmıştır. Bu okullar göstergebilim alanında birbirine yakın çalışma ve araştırmaların ortak bir çatı altında toplanmasına yarar sağlamışlardır. RolandBarthes, Louis Hjelmslev, ClaudeLévi-Strauss, Julia Kristeva, ChristianMetz, Algirdas J. Greimas ve Jean Baudrillard gibi araştırmacılar göstergelerin toplumsal işlevini vurgulayan Saussure'un Avrupa geleneğini; Charles W. Morris, Ivor A. Richards, Charles K. Ogden, Umberto Eco ve Thomas Sebeok gibi araştırmacılar ise göstergelerin mantıksal işlevine vurgu yapan Peirce'in Amerika geleneğini benimsemeyi tercih etmişlerdir (Dervişcemaloğlu, 2005: s.14).

Kuruluşundan bu yana göstergeleri anlamlandırma, çok fazla araştırmacıya ilham kaynağ olmuş ve üzerinde yoğun çalışmalar yapmalarına olanak sağlamıştırRolandBarthes, kendine has yaklaşımıyla daha çok kültür çözümlemeleri üzerinde çalışan çağdaş göstergebilimin önemli isimlerinden birisidir. Yaşamdaki olguları gösterge dizgeleri halinde çözümlemek ve işleyiş kurallarını bulmak için çalışmıştır.

Barthes;(Fiske, 2003: s.63) anlamları, toplumsal ilişkilerin ve toplumsal yapıların içinde oluşturmaktadır. Anlamların kültürel pratikler içinde toplumsal karakterlerin konum ve tavırlarına nasıl etki ettiğini ve işlevselliklerini dilin içinde anlam, kodlar, düzanlamlar, yananlamlar ve mitler adını verdiği düzeylerde yapılandırmaktadır.Barthes bütün bunları anlamlama kavramı aracılığıyla göstergebilime bağlar; göstergelerle ikincil gösterilenler ya da yananlam gösterilenleri arasındaki bağıntılar üzerinde durur.Barthes'ın anlamlandırma sürecinde birinci düzeyi olan düzanlam; göstergenin göstereni ve gösterileni arasındaki ilişkiyi ve göstergenin dişsal gerçekliktekigöndergesiyle ilişkisini betimler. Göstergenin ortak duygusal anlamına gönderme yaparak anlamlandırma sürecine dahil olan aynı düşünceye ulaşılmasını sağlar. İkinci düzey ise yananlamdır.Yananlam; göstergenin, kullanıcıların duygularıyla ya da heyecanlariyla ve kültürel değerleriyle buluştuğunda meydana gelen etkileşimi betimlemektedir (Altuntuğ, 2013: s.132).

20. Yüzyılda göstergebilim alanında çalışmalar yapan Belçikalı göstergebilimci J. Marie Klinkenberg, son derece kısa bir sürede ortaya çıkan yeniliklerin ve eskiden gizemli sayılan tekniklerin geniş kitleler tarafından genelleştirilmesinin, göstergebilim alanındaki çalışmaları ve toplumsal söylemleri de kökten değiştirdiğini savunmaktadır. Klinkenberg'e göre; veriler görsele dönüştüğünde, kullanıcı tarafından algılanmaktadır. Bu durumda da süreklilikten 
yani analog yapıdan söz etmek gerekmektedir. Göstergebilimin nesnesi olan anlam ise süreklilikten doğmaktadır. Özetle anlamlandırmak, aynı zamanda süreklilik kazandırmaktır. Ancak, sürekli olanın (analog) daha sonrasında, iletişim kurmak ve iletebilmek için süreksizliğe (dijitale) dönüşmesi de dikkat çekicidir. Sonuçta, dijital ve analog arasındaki karşıtlıktan çok, bir tür tamamlama özelliği söz konusu olmaktadır (Klinkenberg, 2012: s.16). Birçok kaynaktan beslenen göstergebilimin önemi, teknolojik gelişmelerle birlikte hergeçen gün artmakta ve buna bağlı olarak da çeşitli disiplinlerle ilişki kurmaktadır (www.egeedebiyat.org). $\mathrm{Bu}$ disiplinler arasında yer alan ve 20. yy'ın son çeyreğinden itibaren hızlı gelişimi ile dikkat çeken spor endüstrisi; profesyonel bir süreç çerçevesinde göstergebilim aracılığıla elde edilen göstergelerin değerlendirilmesinianaliz, yeniden üretim ve performans geliştirme alanlarında kullanmaya başlamıştır. Günümüzde, sürekli gelişim felsefesi, etkilerini spor alanında da gösterirken, spor teknolojileri aracılığıyla elde edilen dijital göstergelerin önemi her geçen gün artarak önem kazanmaktadır.

\section{Spor Teknolojilerinde İnovasyon ve Dijital Göstergeler}

İnovasyon, yeni veya önemli ölçüde değiştirilmiş ürün (mal ya da hizmet) veya sürecin; yeni bir pazarlama yönetiminin; ya da iş uygulamalarında, işyeri organizasyonunda veya diş ilişkilerde yeni bir organizasyonel yönetimin uygulanması olarak tanımlanmaktadır (Devecioğlu\&Altıngül, 2011: s.46-47).

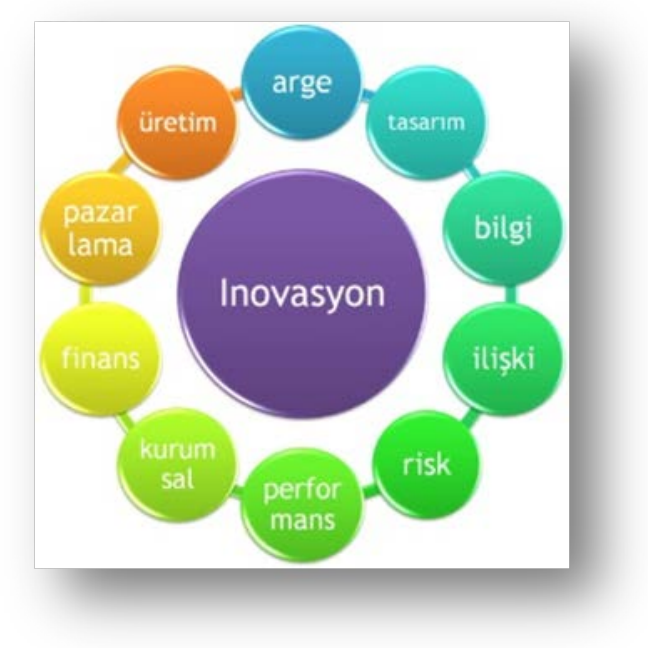

Şekil 1. Inovasyon

Kaynak: http://gelisenbeyin.net/inovasyon.html

İnovasyon kavramının son dönemde popülerleşmesi ise küreselleşme ve gelişmekte olan ülke piyasalarının atılımıyla yakından ilgilidir. Yoğun rekabetin yaşandığı ortamlarda kurumlar;inovasyonlar yoluyla ürün ve hizmetlerini farklılaştırmaya ve girişimlerinin 
karlılıklarını korumaya çalışmaktadırlar. Markalaşma ve marka değeri gibi kavramların ön plana çıkışı da benzer dinamiklerle açıklanmaktadır (http://ekonomiturk.blogspot.com).

Günümüzde sporun; gelişen bilgi - teknoloji ve gittikçe artan boş zaman kültürünün yanı sıra; görsel bir ürüne dönüşmesi ve insanların sağlıklı yaşam, zinde kalma gibi ihtiyaçlarının artması ile birlikte önemli bir mesafe kat ettiği bilinmektedir.

Teknolojideki son gelişmeler sporu şekil olarak geliştirmekte ve yenilemektedir. Birçok ülkede spor teknolojisi üreten sistemler oluşturulmaktadır. Örneğin; top üretimine yönelik birçok firma laboratuarlar ve araştırma geliştirme gurupları oluşturmakta ve endüstri mühendisleri inovatif ürünler geliştirmeye yönelik çalışmalar da bulunmaktadırlar. Spor giysileri üretiminde Nano teknolojiden yararlanılmakta, spor ayakkabıları ve kramponlar, son teknoloji ile üretilmekte, hatta hakemlerin kullandıkları bayraklar, kulaklıklar, düdükler birerteknoloji ürünü olarak sergilenmektedirler. Yayın teknolojilerinde yaşanan gelişimler aracılığıyla gün geçtikçe spor organizasyonları daha fazla insanlara ulaşmaktadır.

Spor tesisleri olarak bilinen geleneksel alanlar, bilgisayar ve elektronik sistemlerin gelişimi ile birlikte, akıllı salonlara ve tesislere dönüşmektedirler. Yeni kamera sistemleri, skorbordlar, bilgisayar sistemleri ile birlikte cep telefonu aracılığ 1 ile hizmete sunulmaktadır. Antrenman bilimciler yeni teknolojinin araç ve gereçlerini kullanarak, spor laboratuarlarında geleceğin sporcularını oluştururlarken, yeni spor sistemlerini bilgisayar ortamlarında maç analizi yaparak geliştirmeye çalışmaktadırlar.

Sporun içerisinde yer alan kontrol sistemleri, hakemler, yöneticiler, bilgi sistemlerinden yararlanmanın yollarını aramaktadırlar. Spor, günümüz teknolojilerinin kullanımı ve yeni teknolojilerin tanıtımı alanında da ayrı bir endüstrinin kapılarını aralamaktadır(Devecioğlu \&Altıngül, 2011: s.47).

Bilginin ekonomik ve toplumsal faydaya dönüştürülmesi olarak tanımlanan inovasyon kavramı (http://gelisenbeyin.net/inovasyon.html)aynı zamanda teknolojik ürün ve süreçlerin geliştirilmesinin yanı sıra, mevcut ürün ve süreçlerde de önemli teknolojik değişiklikleri kapsamaktadır.

Şekil 1'de ifade edildiği gibi inovasyonun bileşenleri göz önüne alındığında; ar-ge, tasarım, bilgi, ilişki, risk, performans, kurumsal, finans, pazarlama ve üretim elemanları ile karşılaşılmaktadır.

İnovasyon tanımdan ve bileşenlerinden yola çıkarak; bilginin faydaya dönüştürülmesi aşamasında, ilişki kurma ve performans artırımında ve sonuçta yeniden üretimde var olan gerçek imaj, dönüştürücü öğe olarak kabul edebileceğimiz makine (araç/sistem) ile simülasyon ortamına aktarılmaktadır. Bu bağlamda, oluşan "sanal imaj", dengeleyici öğe olarak tanımlanabilecek kişi, nesne, vb. ile "yeniden yaratılmakta/üretilmektedir." 


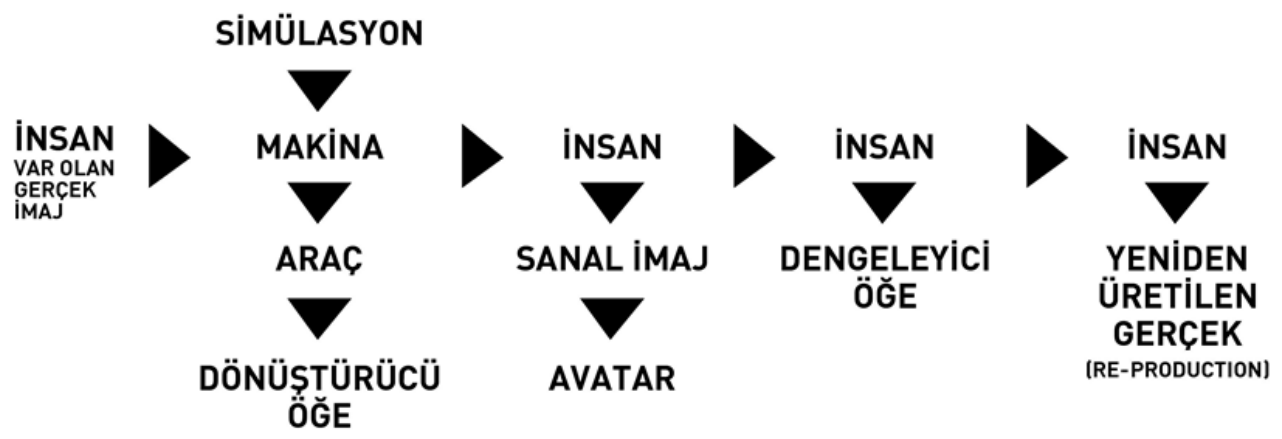

Şekil 2- Teknoloji Aracılığıyla Sanal Gerçeklik ve Yeni Gerçeklik Üretimi Akış Şeması

(Küçükerdoğan, R \& Ekin, V.)

Sonuçta, makine / araç / dönüştürücü öğe gerçeği teknolojinin var olan gerçekliği sanal gerçekliğe ve sonrasında "yeniden gerçekliğin üretimi" sürecine spor endüstrisi açısından bakalım. Spor ve etkileşim sürecinde, dönüştürme eylemi dışındaki tüm evrelerde, insan faktörü yer almaktadır. Buna göre; insan (sporcu), var olan gerçek imajından farklı olarak,inovatifanlayış ve sanal gerçeklik aracılığıyla, "yeniden üretilen gerçek" olaraksahalarda yer alabilmektedir.

\section{3.a) Yöntem ve Amaç}

Bu çalışmada; tümdengelimli, gözleme dayalı (ampirik) yöntem ile durum saptaması yapılmaktadır. Ayrıca çalışmada göstergelerin çözümlenmesi odaklı bir medya taraması da yapılmıştır.Temsil edilme işlevini yerine getiren göstergelerin belirlenmesi ve gerçekliğin bileşenlerinin iyileştirilmesi ve dönüştürülmesi sürecinde teknolojiyi temsilen, sanal gerçeklik uzamlarının oluşumuna olanak sağlayan robot göz (roboticeye) uygulamalarının Türkiye'deki örnekleri ve medya yansımaları üzerinde durulmaktadır.

\section{3.b) Örneklem}

Türkiye ve Avrupa'nın köklü spor kulüplerinden biri olan Fenerbahçe SK. ve profesyonel futbol takımı, 2012 yılından itibaren, antrenman sahası olan Dereağzı Tesisleri ve Şükrü Saraçoğlu Stadyumu'nda, teknik alt yapısını oluşturarak uygulamaya geçirdiği, sanal gerçeklik uzam ve verileri sağlayan robotik göz sistemini Türkiye'de uygulamaya geçiren ilk spor kulübü olması nedeniyle, çalışmanın örneklemi olma özelliğini taşımaktadır. 


\section{3.c) Hipotez}

Dünyadaki teknolojik gelişmelerle birlikte, spor alanında yaşanan üst düzey rekabet ortamlarına ve küreselleşme süreciyle paralellik gösteren sporun endüstriyelleşmesine uyum sağlama çabası gösteren Türk spor kulüpleri; öncelikle futbol alanında; sanal gerçeklik uzamları ve dijital verilere bağlı olarak, sporcu ve takım performanslarının iyileştirilmesi yönünde adımlar atmaktadırlar.

\section{Spor ve Sanal Ortam Göstergeleri Uygulama Örneği: RoboticEyeve Göstergeler}

Spor ve sanal ortam göstergeleri ilişkisini irdelemeden önce, sanal gerçeklik kavramı üzerinde durmakta fayda bulunmaktadır. Buna göre; literatürde sanal gerçeklik kavramının farklı tanımlarına rastlamak mümkündür. Robert Stone'un ve Charles Oppenheim'ınyaptığı tanımlar, diğer tanımları da özetlerniteliktedir.Stone'a göre; sanal gerçeklik insan ve makine arasındaki iletişimi artırmak için geliştirilen, insan duyularınahitap eden bir çokluortam (multimedia) dir(J. Robert, 1991: s.283-300). Oppenheim'agöre ise; sanal gerçeklik, insanmakine etkileşimini, görsel ve işitsel iletişimle yetinmeyip, hissetme yoluyla artırmaya çalışan bir teknolojidir (Oppenheim, 1993: s.215-227). Sanal gerçeklik teknolojisi ile yapılmaya çalışılan, insan-makine iletişimini artırmak için insanla makine arasındaki engellerin ortadan kaldırılmaya çalışılmasıdır (Kurbanoğlu, 1996: s.21).Bu bağlamda, sanal gerçeklik teknolojisi ile yepyeni bir spor dünyasına sahipolmak da mümkündür. Bir görüntü yakalama sistemi olarak tasarlanmış olan ve HD kalitesinde görüntü alabilen "Robotik Göz"; yeni bir uygulama olarak, spor alanında göstergelerle değerlendirme ve iyileştirme olanağ 1 sunan bir teknolojik ürün olma özelliğini taşımaktadır. Sistem, Türkiye'de ilk kez Fenerbahçe SK. Profesyonel futbol takımında uygulanmaya başlamıştır.

Sporcu performansları ile birlikte, rekabet analizleri hazırlama imkanı da sunan“Robotik Göz"; otomatik olarak kaydettiği görüntüleri, video formatında kullanıcılarına iletebilmekte, sanal ortamda "gösterge" özelliği taşıyan pek çok veriyi kullanıcıların dikkatine sunabilmektedir (http://mebcn.com/what-we-o/theory/documentation/robotic).

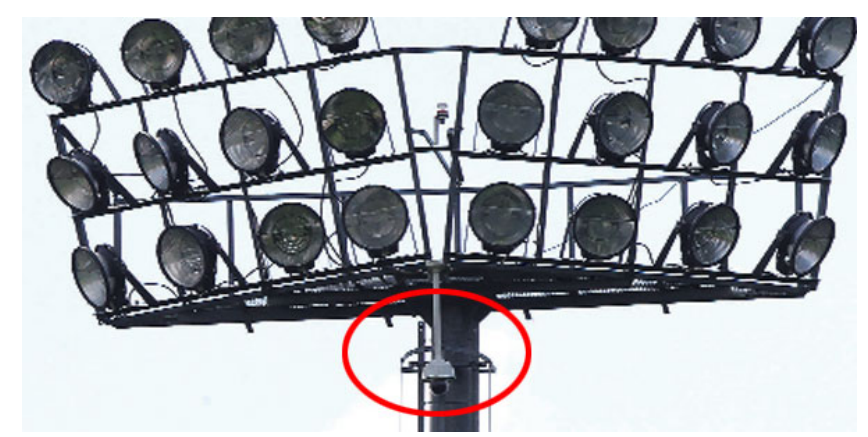

\section{Resim 1 - Robotik Göz Uygulama Örneği}

"Robotik Göz" uygulamasına bağlı olarak, aydınlatma direklerine takılan kameralı sistemler, maç ve antrenman sırasındakuşbakışı olarak görüntü kaydedilirken, futbolcuların pas ve pozisyon hatalarını takip etme imkanı sunmaktadır. Aynı zamanda elde edilen görüntülü verilerin yanı sıra, GP SportAnalyse isimli program aracılığıyla da oyunculara idman öncesi 
polar saat ve yelekler dağılırken, futbolcuların çalışma temposu ve üzerlerine fazla yük binmesi nedeniyle oluşabilecek sakatlık riskleri de belirlenebilmektedir(Sözcü Gazetesi, Spor sayfası, 10 Temmuz, 2013).

Sistemle, koşu mesafelerinin ölçümündeki faydasız koşular çıkarılarak, gerçek performans değerlerine ulaşılabilmekte ve oyuncuların hamle yanlışları yine sistem tarafından tespit edilebilmektedir (www.takvim.com.tr/Spor/2013/09/12/ersun-yanal-sahayi-robot-gozuyleizliyor).

Türkiye'den Fenerbahçe SK'nın yanı sıra bu sistemden;FC Barcelona, Roma, Udinese, Benfica, Villarreal, Maccabi Tel Aviv ve Dinamo Tiflis gibi futbol kulüpleride yararlanmaktadır. Aynı zamanda, Barcelona Basketbol Kulübü, Katalan Tenis Federasyonu da bu sistemi kullanmaktadır.

\subsection{Teknik Göstergelerle RoboticEye}

"Robotik Göz" uygulamasında, çekilen görüntüler 4 farklı açıdan HD kalitesinde sisteme aktarılmaktadır. Kamera açıları sayesinde pozisyonlar optimum seviyede yeniden yapılandırılmakta ve 19 inçlik dokunmatik ekranlar, aynı zamanda özel joysticklerle kontrol edilebilmektedir. Görüntüler, basit ve sezgisel ara yüzlerle teknik ekibe detayları yakalama konusunda doğru bilgiler aktarabilmektedir.Aşamalı tarama yapılarak kaydedilen görüntüler, her türlü harekete rağmen kristal netliğini garanti ederken, antrenman ya da karşılaşma biter bitmez görüntülere iç ağ bağlantısıyla kolayca erişim imkanı sağlamaktadır. Bununla birlikte, "RobotikGöz"ün en önemli avantajlarından biri de piyasadaki birçok analiz programıla uyumlu bir şekilde çalışabiliyor olmasıdır. Sistem aynı zamanda, bilgi depolaması ve teknik analizler açısından da teknik ekibe önemli imkanlarsağlamaktadır.

Sistemin çalışması ile birlikte 'kontrol noktası' olarak adlandırılan ekranlardaki görüntüler, 'server' (sunucu) üzerinden A Takım, Akademi\&Yedek Takım ve Altyapı Birimleri'ne gidecek şekilde üç bölüme ayrılmaktadır.Buna göre;

A Takım : Teknik direktör, yardımcı antrenör,kaleci antrenörü, analist ve fitness koçu,Akademi ve Yedek Takım :Akademi koordinatörü, teknik direktör ve analist,Alt Yapı : Sportif direktör, teknik birim ve scout ekibinden oluşmaktadırlar ve birimler arasında uyumlu bir çalışma metodunun belirlenmesi esas alınmaktadır(www.ligtv.com.tr/haber/kadikoye-guardiolasistemi).

Sporda sanal ortam göstergelerinin, anlamlandırma (durum değerlendirmesi) aşamasında, performans artırılmasındaki olumlu yöndeki etkilerine örnek oluşturan bu uygulamanın işleyiş sürecini "sporcu - teknoloji etkileşiminde sanal gerçeklik ve yeni gerçeklik modeli" çerçevesinde değerlendirmek mümkün olmaktadır. 


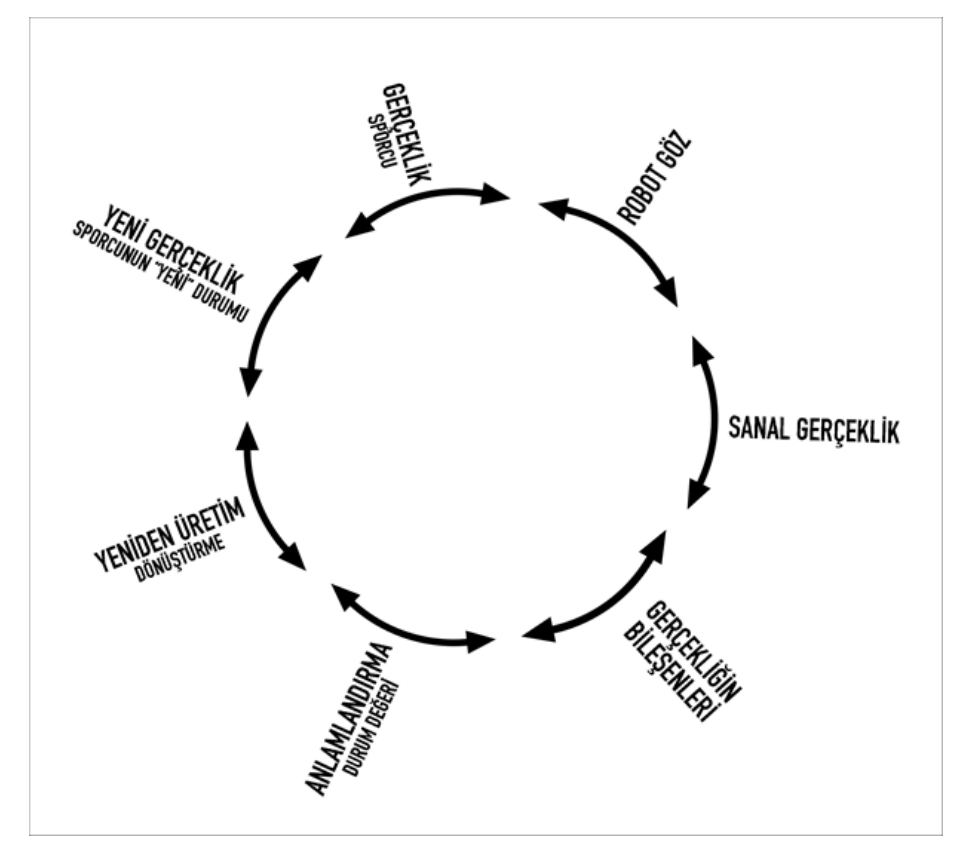

Şekil 3- Sporcu - Teknoloji Etkileşiminde Sanal Gerçeklik ve Yeni GerçeklikModeli ( Küçükerdoğan, R \& Ekin, V.)

Bu bağlamda; gerçeklikle başlayan sürecin robot göz aracıllı̆ıyla sanal gerçekliğe dönüştüğü, gerçekliğin bileşenlerinin anlamlandırma ile yeniden üretime ve yeni gerçekliğe dönüşümüne tanıklık edilmektedir. Türkiye gibi, özellikle köklü bir futbol kültürüne sahip olan ülkede; spor sahalarında yaşanan rekabet, toplumsal ve kültürel değişimlerle birlikte, teknolojik gelişimleri de çok çabuk bünyesine katabilen bir yapıya sahiptir.

Rekabette farklılı̆̆ı yakalayabilmek, büyümek, şampiyonluklar yaşamak, zenginleşmek, ulusal başarılar yanında uluslararası başarılara ulaşmak, taraftarı mutlu etmek, marka değerini artırmak, ayrıcalıklı bir yapıya sahip olmak, başarılı alt markalar oluşturmak, sivil bir insiyatif olabilmek, kurumsallaşmak gibi hedeflere sahip kulüplerin, en modern tesislere ve en son teknolojiye sahip olma arzuları da beraberinde her geçen gün kendini daha netolarak hissettirmektedir.

Özellikle,kitle iletişim araçları yardımıyla, kulüplerin taraftarları ile kurmaya çalıştıkları sağlıklı iletişim ve konumlandırma süreçlerinde, medya önemli bir görev üstlenmektedir.

Günümüzde spor kulüpleri, medyanın gücünün bilincindedirler. Aynı zamanda medya yansımalarının etkilerinin de farkında olmaktadırlar. Bu bağlamda, teknolojiyi kullanmanın yanı sıra, çağdaş bir kurum imajı yaratmanın da önemi üzerinde durmaktadırlar.

\section{Sonuç}

Günlük yaşantımızda, görüntülerin bizleri sarmaladığına dikkat çeken Küçükerdoğan, aynı zamanda; okuduğumuz dergide, bazen kullandığımız ilaç kutusunda, televizyonda, bilgisayarda ve benzer birçok ortamda sayısız görsel ileti ile karşılaştığımıza dikkat 
çekmektedir. Görselliğin,yaşadığımız yüzyılda ne kadar önemli olduğunun altını çizenKüçükerdoğan'a göre; görüntü ve görsel iletiler bizi sadece eğlendiren, anlamamızı, algılamamızı kolaylaştıran şeyler değil, aynı zamanda bir konuya yoğunlaşmamızı ve dikkat etmemizi sağlayan bir yöntem, bir süreçtir (Küçükerdoğan,2012: s.55). Bu açıdan bakılınca, XXI. Yüzyılinsanının her dönemden daha fazla göstergelerle kuşatıldığı ve göstergesiz bir yaşamın olanaksız hale geldiği görülmektedir.

Anlam, anlamlandırma ve göstergelerin yorumlanması açısından çok hızlı ve sürekli değişim gösteren süreçleri yaşamaktayız. Günümüzde kullanılan iletişim alan ve araçları ile bilgisayar programlarını göz önüne aldığımızda, yakın gelecekte en fazla gelişim gösterecek alanlardan birinin de göstergebilim olacağını ön görebiliriz. Göstergelerin anlamlandırılması ve yorumlanması, teknolojik gelişmelerle doğrudan ilintili olmaktadır (Günay \& Parsa, 2012: s.78). Teknolojik gelişmelerin ulaşmış olduğu noktanın önemli bir göstergesi de sanal gerçeklik ortamlarıdır.

Sanal gerçeklik ortamları, kapalı bir sistem oluşturmasından dolayı, sistemin kendi içerisinde tutarlı, kontrol edilebilir bir bütün oluşturmasını sağlayabilme yetisine sahiptir. Doğası gereği,sanal gerçeklik ortamında belli bir konuda farklı uygulama ve modeller geliştirilebilmektedir (Kuruüzümcü, 2010: s.94). Böylece, farklı bakış açıları ve alanlarda inceleme, ar-ge imkanları söz konusu olabilmektedir.

Sanal gerçeklik ortamlarında objelerin tümdengelimli yapıları dönüştürülebilmekte, benzeşimle yeni yaratım ve dolayısıyla da iyileştirme olanakları elde edilebilmektedir.

Çalışmaya konu olan "robotik göz" uygulaması bu doğrultuda sanal gerçeklik ortamı yaratarak spor endüstrisi içinönemli göstergeler ortaya çıkarmaktadır. Söz konusu göstergelerin performans artırımı amaçlı bilgiler vererek yeniden üretim sürecinde işlev gördüğünüsöyleyebiliriz. Elbette spor ile yakın ilişki içerisinde bulunan medyanın da bu gelişmelere kayıtsız kalmadığı gözlemlenmektedir. Örneğin; 2 Temmuz 2013 tarihli Fanatik gazetesinin haberinde, Fenerbahçe SK'nın antrenmanlarında "RoboticEye" sistemini kullanmaya başlayacağı, takip eden dönemde Fenerbahçe Şükrü Saraçoğlu Stadı'na da aynı sistemin kurulacağından kamuoyunu haberdar etmektedir.

\section{Antrenmanda "RoboticEye"}

Fenerbahçe, 2013-2014 futbol sezonunun hazırlıklarını yaptığı antrenmanla sürdürdü.

\section{"RoboticEye" devrede}

Sart-lacivertli futbolcularm antrenman performansı "RoboticEye" kamera sistemiyle takip ediliyor.

Aydınlatma direğine takılan kameralı sistemle, antrenman sırasında saha içi kuşbakışı olarak kaydediliyor.

Futbolcuların pas ve pozisyon hataların takip etmek için kurulan sistemin Fenerbahçe Şükrü Saracoğlu Stadı'nda da kurulacă̆ı ifade edildi (www.fanatik.com.tr/antrenmanda-roboticeye_3_Detail_34_319626.htm). 
Konuyla ilgili yapılan medya taraması sonucunda,4 Eylül 2013 tarihli Skorer haber sitesinde yer alan haberdespor gündemini oldukça meşgul eden bir konu haline gelen, M. Sow'unlig maçlarında ilk onbir'de yer almaması konusu ele alınmıştır. Haberde, oyuncunun kadroda bulunmamasına gerekçe olarak,“Robotik Göz" uygulaması raporları gösterilmektedir.Türk medyasında ender olarak görülen, sağlık raporları ya da ceza uygulamaları dışında, teknik nedenlerle kadroya alınmama nedeni, büyük puntolarla okurlara duyurulmuş, böylece spekülasyonlara yol açan bu kararın, gerçekte yeni teknoloji ürünü olan bir sanal uygulama sonucunda alındığ1 ortaya çıkmıştır(http://skorer.milliyet.com.tr/sow-gps-e-yakalandifenerbahce/detay/1758720/). Sonuçta,RoboticEye'dan elde edilen sporcu ile ilgili göstergeler doğrultusunda, yeni bir teknoloji ve sanal ortam etkileşimi sonucu sporcunun performansi ile ilgili karar verilmiştir.

Çalışmanın hipotezinde de belirtildiği gibi dünyadaki teknolojik gelişmelerle birlikte, Türkiye'de de spor alanında yaşanan üst düzey rekabet ortamlarına ve küreselleşme süreciyle paralellik gösteren sporun endüstriyelleşmesine uyum sağlama çabası gösteren spor kulüpleri; öncelikle futbol alanında sanal gerçeklik uzamları ve dijital verilere bağlı olarak, sporcu ve takım performanslarının iyileştirilmesiyönünde olumlu yönde adımlar atmaya başlamışlardır.

Daha önce sözünü ettiğimiz şekil 3'deki gibi, "roboticeye" uygulaması ile sporcunun gerçekliği "sanal bir gerçekliğe" dönüşmektedir. Sanal gerçekliğin anlamlandırılması ise hiç kuşkusuz, göstergeler aracılığıyla olmaktadır.

Aynı zamanda, spor kulüplerinin bu hamlelerinin medya yansımaları dadikkat çekmektedir. Geleneksel ve yeni medyada; teknoloji, sanal gerçeklik ortamları, göstergeler ve durum değerlendirmeleri aracılığıyla,sporda endüstriyelleşme sürecinin bir parçası olarak rekabet ortamında öne çıkma çabaları söz konusu olabilmektedir.

Yakın gelecekte, bilimsel çalışmaların,pek çok alanda olduğu gibi spor alanında da göstergebilimden daha yoğun bir biçimde faydalanacağı ön görülmektedir. Bunun da en basit örneği çalışmamıza konu olan "roboticeye" uygulamasıdır.

Ülke sporunun dinamosu niteliğindeki spor kulüpleri, küreselleşen dünyada,sporun endüstriyelleşmesi sürecinde;Berger'in de belirttiği gibi "konuşmaya başlamadan önce tanımayı öğrenen bir çocuk konumundan" (Berger, 2004: s.7) konuşan ve söz sahibi olan konumuna bilimsel yöntemlerin desteğiyle gelebileceklerdir. 


\section{Kaynakça}

Altıngül, O, Devecioğlu, S. (2011). “Spor Teknolojilerinde İnovasyon",6.International Advanced Technologies Symposium (IATS'11),16-18 May, 2011, Elazı̆̆, Türkiye.

Altuntuğ. Meltem. (2013). “Türk Halk Oyunları'nda Dansçı Ve Oyun Etkileşiminin Ürünü Olan Naraların Göstergebilimsel Yaklaşımla İncelenmesi”. Uşak Üniversitesi Sosyal Bilimler Dergisi, 2013 Kış (6/1).

Berger, John. (2004). “Görme Biçimleri”, Metis Yayınları, İstanbul.

Deely, John. (1990). “Basics of Semiotics”, Indiana UniversityPress, Bloomington,theU.S.A.

Dervişcemaloğlu, Bahar.“Temel Göstergebilim (Semiyotik) Kavramlan Üzerine Bir İnceleme", Yayınlanmamış Yüksek Lisans Tezi, Ege Üniversitesi Sosyal Bilimler Enstitüsü, İzmir.

Fiske, John.(2003). “İletişim Çalışmalarına Giriş”, Bilim ve Sanat Yayınları, Ankara.

Günay, V. Doğan, Parsa, Alev F. (2012). “Görsel Göstergebilim - İmgenin Anlamlandırılması", Es Yayınları, İstanbul.

Klinkenberg.J. Marie "Dijitalden Analoğa Gidip Gelmek", Visualist2012, Uluslararas1 Görsel Kültür Kongresi - İletişimde, Sanatta ve Tasarımda Yeni Yaklaşımlar “Dijitalleşme", 07-09 Mart 2012, İstanbul, CİLT I, s. xvi.

Kurbanoğlu,S.Serap. (1996). “Sanal Gerçeklik: Gerçek Mi, Değil Mi?”, Türk Kütüphaneciliği 10,1(1996),s.21-31.

Kuruüzümcü, Riza. (2010).“Bir Dijital Ortam ve Sanat Formu Olarak Sanal Gerçeklik”, Sanat Dergisi, İstanbul.

Küçükerdoğan, Rengin. (2012). “Görsel İletişim, Göstergeler ve Anlam Aktarımı: Görsel İletide"Pencere" İmgesi”, Der.V. Doğan Günay, Alev Parsa. "Görsel Göstergebilim - İmgelerin Anlamlandırılması, Es Yayınları, İstanbul.

Oppenheim, Charles. (1993). “Virtual realityandthevirtuallibrary”, Information

Services andUse (13):215-227.

Parsa, Seyide, \& Parsa, Alev Fatoş (2004). “Göstergebilim Çözümlemeleri”, 2. Baskı, Ege Üniversitesi Basımevi, İzmir.

Rifat, Mehmet. (1990). “Dilbilim ve Göstergebilimin Çağdaş Kuramları”,Düzlem Yayınları, İstanbul.

Rifat, Mehmet.“Göstergebilimin ABC'si”, Simavi Yay., 1992,İstanbul.

Stone, Robert J. (1991). “Virtual realityandcyberspace: Fromscience fiction toscience 
Fact", Information Services andUse (11).

Vardar, Berke. (1998). “Dilbilimin Temel Kavram ve İlkeleri", Multilingual Yayınları, İstanbul, s.86-87.

Yengin, Deniz. (2012). “Yeni Medya ve Dokunmatik Toplum”, DERIN Yayınları, 1.Baskı, İstanbul.

\section{İnternet kaynakları}

Dervişcemaloğlu, Bahar.Göstergebilim.www.ege-edebiyat.org.(01.10.2013).

Özgür, Ahmet http://www.ahmetozgur.com/akademik/gostergebilim(01.10.2013).

http://ekonomiturk.blogspot.com/2010/03/inovasyon-nedir-inovasyon-ne-demek.html (01.10.2013).

http://www.takvim.com.tr/Spor/2013/09/12/ersun-yanal-sahayi-robot-gozuyle-izliyor

http://gelisenbeyin.net/inovasyon.html (01.10.2013).

http://mebcn.com/what-we-do/theory/documentation/roboticeye-football(01.10.2013).

http://www.ligtv.com.tr/haber/kadikoye-guardiola-sistemi (01.10.2013).

http://www.fanatik.com.tr/antrenmanda-robotic-eye_3_Detail_34_319626.htm (01.10.2013).

http://skorer.milliyet.com.tr/sow-gps-e-yakalandi-/fenerbahce/detay/1758720/default.htm (01.10.2013).

\section{Diğer kaynaklar}

Sözcü Gazetesi, Spor sayfası, 10 Temmuz, 2013. 
AJIT-e: Online Academic Journal of Information Technology

2013 Fall/Güz - Cilt/Vol: 4 - Sayı/Num: 13

DOI: 10.5824/1309-1581.2013.4.001.x 